\title{
Concept of an Assisting Tool in the Design and Development Process of a Product with the CPS - A Case Study
}

\author{
Jerzy POKOJSKI ${ }^{\mathrm{a}, 1}$, Lech KNAP $^{\mathrm{b}}$ and Michał TROJGO ${ }^{\mathrm{b}}$ \\ ${ }^{a}$ Institute of Machine Design Fundamentals, Warsaw University of Technology, Poland \\ ${ }^{\mathrm{b}}$ Institute of Vehicles, Warsaw University of Technology, Poland
}

\begin{abstract}
The work concerns the concept of assisting software supporting the design process of a selected class of the CPS (Cyber-Physical System) - a tractor drive system. The task was carried out in a process-oriented convention. The paper presents the characteristics of individual stages of the design task - the design of the tractor transmission electronic unit treated as a design case. To the classic substantive-model-staged narration, the characteristics of existing, acquired, developed and used personal knowledge of designers have been added. Attention was paid to the process, product models, requirements and constraints, aspects of analysis and synthesis, automation tools, and wider contexts of particular issues. The material collected in terms of the personal knowledge served to create the concept of an assistive system for designers to improve the design process through more precise and problem-dedicated knowledge and design models management. The proposed concept is based on design knowledge modelling and can be applied in the design process of the CPS or its elements.
\end{abstract}

Keywords. Design of CPS, Engineering Knowledge Modelling, Design Assistant, Case Study

\section{Introduction}

The purpose of the work was to create a concept of assistive software, developed for designers, supporting the design process of the product treated as a CPS system. The authors decided to consider carefully the real-world task of designing the CPS system, implemented in a process-oriented convention, consisting of certain stages of the tractor transmission electronic unit (TCU) design process [1]. Characteristics of existing individual stages, acquired, developed and used personal knowledge of designers [2] have been added to the classic substantive-model-stage narration. Attention was paid to process and product models, requirements and constraints, aspects of analysis and synthesis, automation tools, and wider contexts of particular issues [3, 4]. The material was collected in terms of personal information and knowledge $[2,5,6]$. That information and knowledge was the result of the project realization, and was used to create the concept based on design knowledge modelling of an assistive system for designers of the CPS or its elements. The main task of the

\footnotetext{
${ }^{1}$ Corresponding Author, Email: jerzy.pokojski@pw.edu.pl.
} 
newly created tool concept is to support the multidisciplinary design process through more precise and problem-dedicated knowledge and design model management [7].

\section{Related work and state of the art}

\subsection{Design of CPS}

Designing of CPS-class systems and designing of machines with CPS elements is a relatively new area of research. Although in the literature we can find many works related to this subject (e.g. [10-12]), majority of them concern the perspective narrowed down to a specific class of cases or solutions (e.g. [10]). Relatively few of them propose more general and universal approaches [11-12]. The authors of this work were the developers of a real industrial project, the aim of which was to design a specific technical system with CPS elements. The project was implemented using classical design methods. One of the final conclusions was the suggestion of the whole process improvement by creating a concept and then building a dedicated environment supporting this class of tasks in the following areas: informal and formal knowledge consolidation/ storage/ management [14], creation and simulation / analysis of CPS models [10-12], supporting decision-making processes in design [2].

\subsection{Engineering knowledge modelling}

The issues of engineering design knowledge acquisition, storage, and sharing are increasingly recognized as a priority. The following facts contributed to this: a significant increase in the complexity of project tasks (this is particularly evident in systems with CPS elements - the design space is significantly extended in relation to tasks without CPS), in projects it is necessary to cooperate and exchange information among many specialists from various disciplines (typical situation in CPS projects), it often takes place in a distributed environment, it is necessary to share information explaining and justifying certain design decisions.

\subsection{Characteristics of the proposed approach}

The characterization of the problems presented in the previous subsections recognizes the duality of project knowledge: a) informal knowledge close to the designer, b) formal knowledge, which gives the basis of simulation, analysis, etc. The completed project task showed that the design of the considered class of systems is in fact a penetrating and intensively cooperative combination of both knowledge approaches. This fact has also become the basis for creating the concept of an environment that supports designers. In many design processes (including the process presented in this paper), in which there are CPS elements, a very intensive, group conceptual design is necessary. It is a phase divided over the time in group sessions and individual work (or in small teams). There can be many such cycles: group sessions - individual work. The achievements of these stages are usually encapsulated in informal and formal knowledge forms. Sometimes, several alternative project threads are developed in parallel. The emergence of formal models allows both the use of specific tools for simulations and analyses as well as computer methods for supporting decision-making 
processes. It is important to quickly and efficiently implement individual actions which means: modelling, integrating and making decisions. The informal knowledge can serve as a source of information about the knowledge processed in the project and become the basis for the development of automation tools [3, 4].

The above conclusions also determined the structure of the whole work. Chapter 2 introduces certain selected topics of the exemplary project. Chapter 3 presents the characteristics of the completed project task. Chapter 4 is a presentation of the concept of the assisting computing environment.

\section{Characteristics of the analyzed project task}

The case analyzed in the present work is the process of designing the TCU of the transmission in a tractor. The transmission system consists of a mechanical system controlled and managed with the developed electronic system. These systems are additionally connected with multiple sensors and actuators. All these components are controlled by dedicated software and composed into the designed CPS.

The project was developed by a company carrying out specialized projects for one of the tractor manufacturers. The tractor manufacturer has developed a new generation of transmission for an agricultural tractor. The main component of the transmission is a section with 4 gears switchable under the load and with forward / reverse gears. All these gears (as well as PTO drive, front drive and differential lock) are controlled by switching on / off the multi-plate clutches controlled hydraulically by means of electromagnetic proportional valves. The transmission is also equipped with a whole range of other functionalities like brakes, 3-point tractor hitch, etc.

Fig. 1 shows schematically the course of the TCU design process, meeting the set of all identified requirements. Certain issues arising from the need to limit the amount of data presented and its confidentiality are omitted in the description. The TCU design and construction process began with activity (1) covering the initial analysis of customer requirements. After analyzing and accepting the solutions proposed in the preliminary project - including manufacturing requirements and abilities as well as proposed algorithms for software operation - a design for the implementation of the TCU was developed.

Fig. 2 presents the example of project activity implemented as a multidisciplinary design task, hereinafter related to the task of multidisciplinary optimization. These tasks were applied respectively in activities (3) at the beginning and (16) at the end of the design process presented in Fig. 1. The optimization task - or rather the decisionmaking process, the inputs to which were the results of the analysis of the results (15) of experimental research (14) - was based on the use of the knowledge and the intuition of the involved engineers of various disciplines: hydraulics, mechanics and electronics. For the correct operation of the transmission it was necessary to solve the task of the cooperation and integration of hydraulic, electronic and mechanical elements.

In the first stage, tasks representing individual disciplines were analyzed as separate and decomposed (15A1-15A3). The solution of problems related to the operation of the hydraulic system allowed for the development of gears' optimal shifting characteristics (by assigning optimal characteristics of proportional valves controlling multi-plate clutches). 


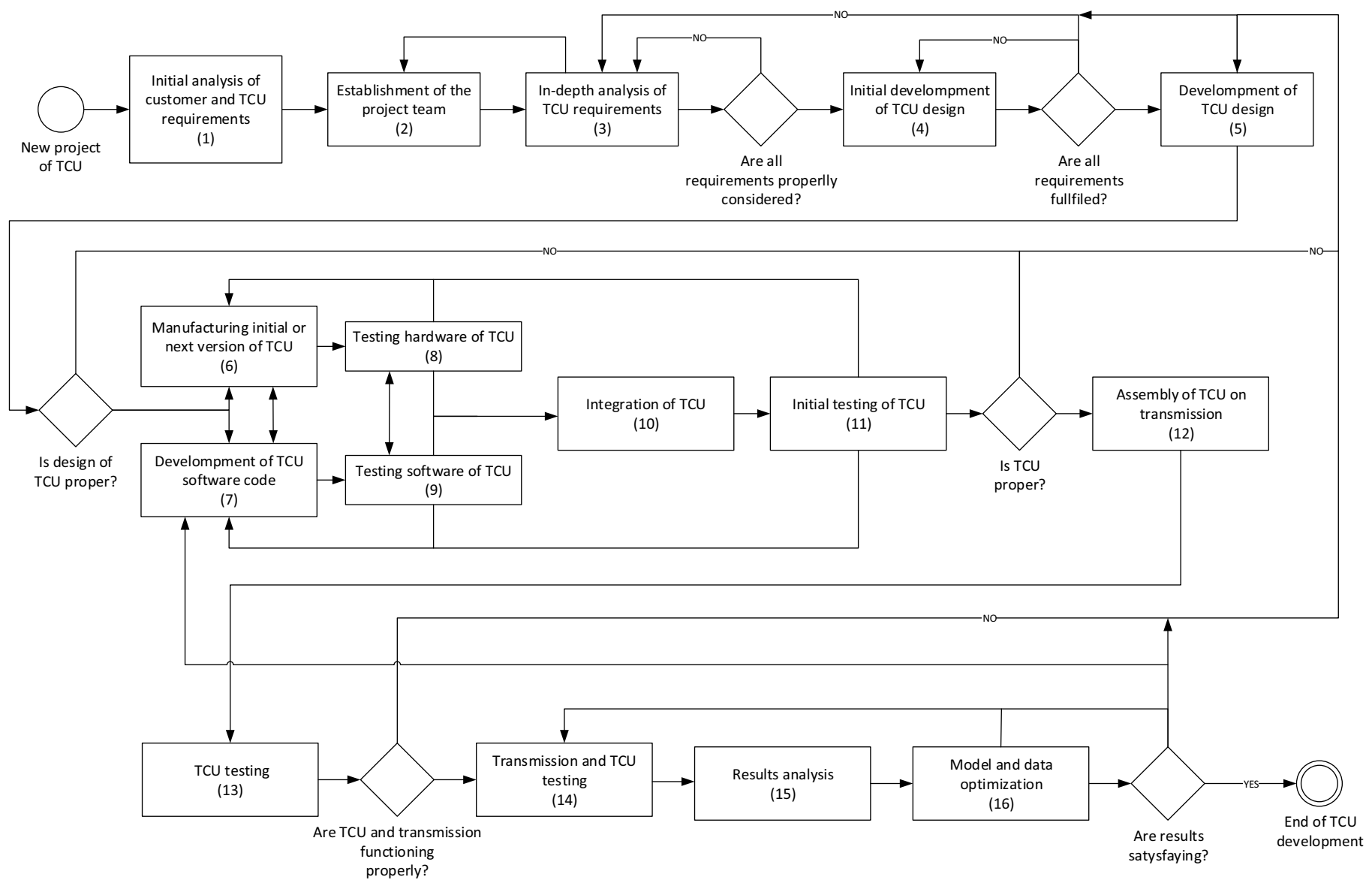

Figure 1. Diagram of the design process of the TCU controller for the transmission of an agricultural tractor. 


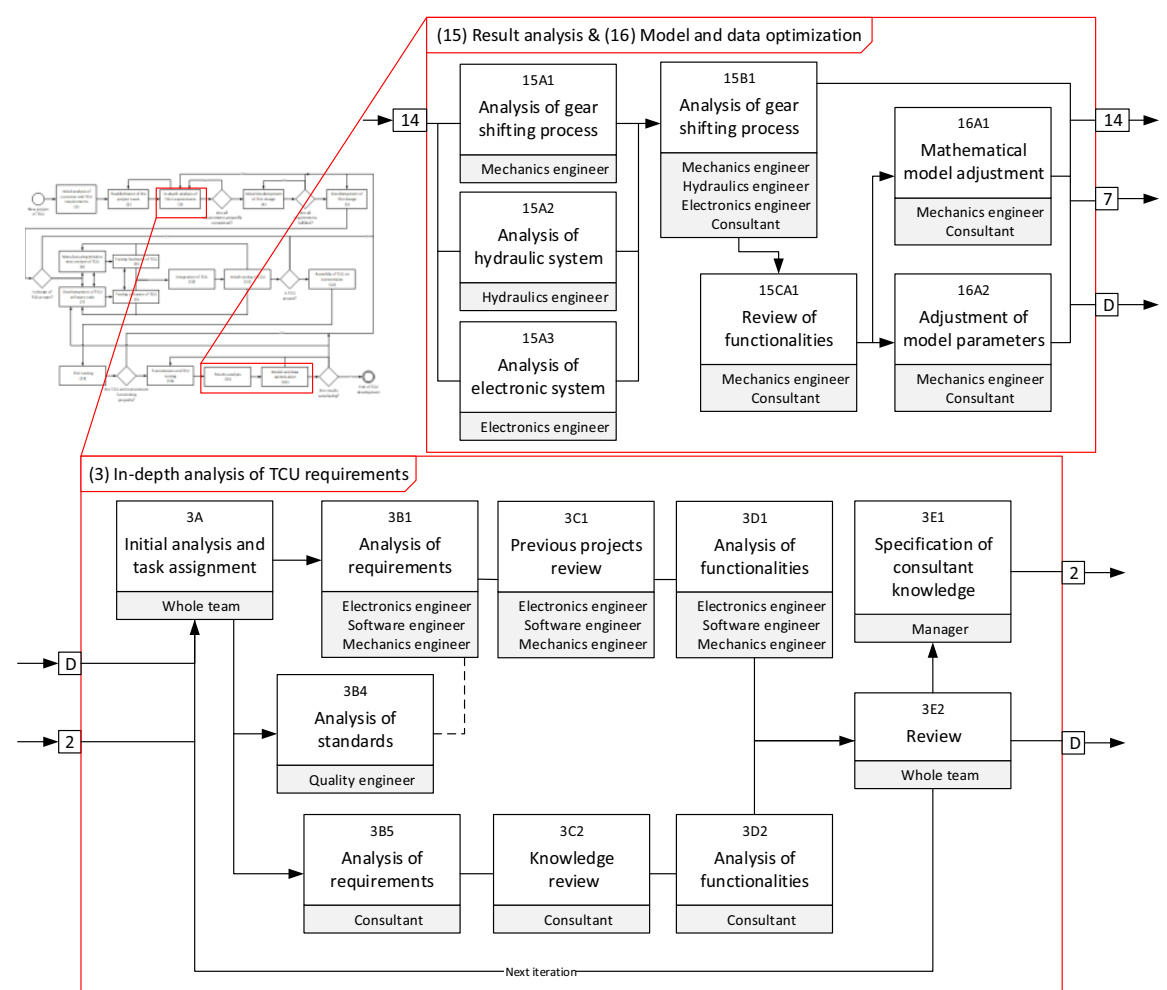

Figure 2. Examples of project activities implemented in a locally integrated manner in the first phase.

An example appearance of the control characteristics of proportional valves is shown in the diagrams at the top in Fig. 3. In the diagrams the green line indicates the value of current intensity (expressed as the Pulse-Width Modulation value - PWM\%) of the disengaged clutch valve, and the red line of the engaged clutch valve. The black line describes the variation of the tractor's speed resulting from the change of the gear. In the left graph the characteristics are shown in the initial form while on the right after optimization. The comparison shows that in the case of optimized switching characteristics there are no noticeable drops in tractor's speed. This is particularly important when switching gears during work of the tractor under heavy load.

The optimization process shown in Fig. 3 can end in three different ways. If it is necessary to rebuild the TCU software, it is possible to return to the operation (7) from Fig. 1. In the case when only adjustment of the switching characteristics parameters was required the previous operation can be reactivated (14) - that is, for retesting the transmission with new parameters of valves' characteristics. If the case of optimal switching of all gears in the transmission is achieved, it is possible to close the optimization task by outgoing through the port (D).

The described operation related to optimization is characteristic for the first cycle of the TCU design process. As a result of the conducted work cycle, an experience was obtained that can be used to replace the knowledge of consultants and engineers with software which relies on appropriate optimization criteria. Thanks to this, it will be possible in the future to carry out activities (14-16) in the manner shown schematically in Fig. 4. It is visible that all works related to the selection of proper characteristics can be automated by dedicated software. 


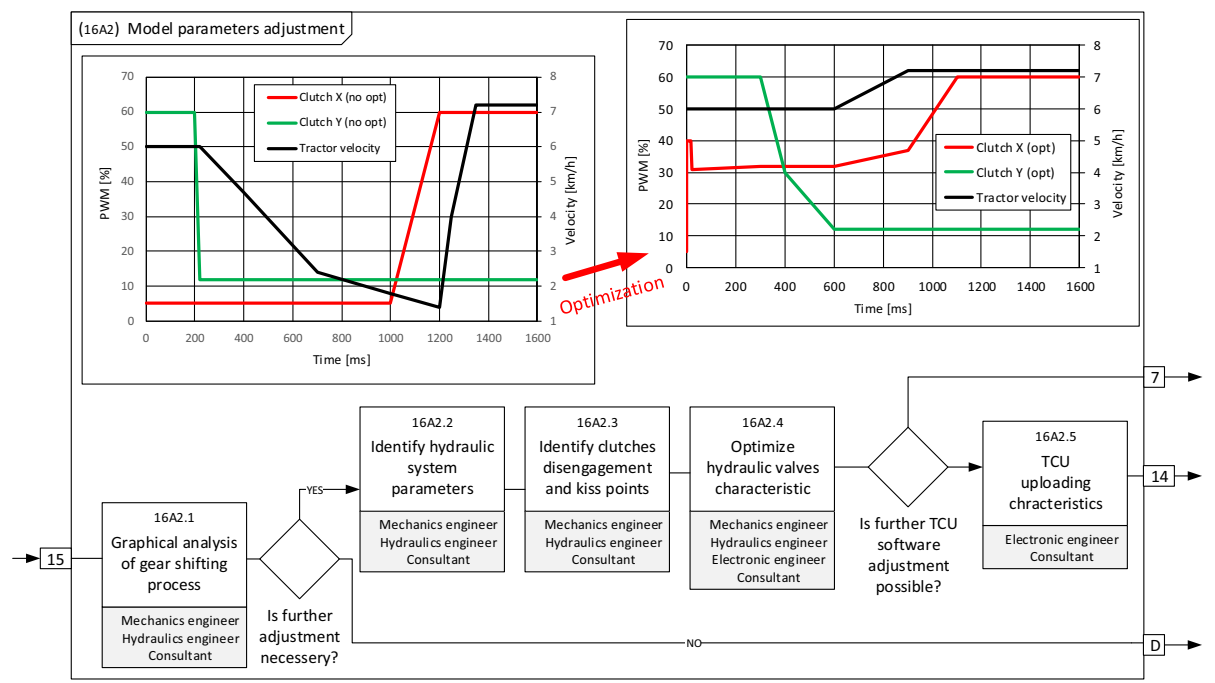

Figure 3. An example of a fragment of a process dedicated to the creation of the concept of CPS system elements.

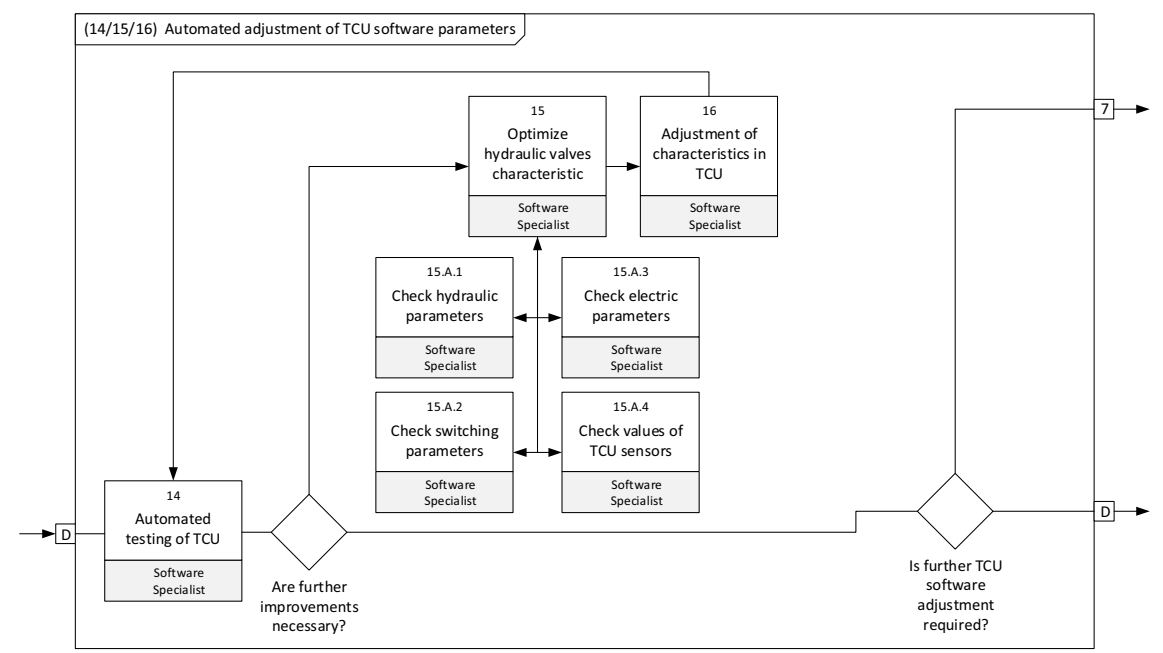

Figure 4. An integrated fragment of the implemented process.

\section{Characteristics of the design process - the perspective of the task being analyzed}

\subsection{General problem structure}

In fact, when we look at the TCU design task and the process of solving it, it is very difficult at the beginning to capture its real scope, available sources of knowledge and models [8, 9] (Fig. 1). Usually, it is possible to see the basic requirements and identify functionalities. But the process of checking individual requirements and characteristics takes place in the range initially perceived (e.g. marked in Fig. 2). The problem is 
decomposed and specialists dealing with individual partial tasks are separated. Usually, they work individually or in small sub-teams. They use their knowledge, and their own and other available models and tools. The partial results obtained are confronted and compared. As a result, we can see that initially elementary design-decision problems are modelled (each of them engages 1-2 people). Rational solutions are noticeable for these small tasks. Different approaches are used: mental simulations [2, 3, 4], checking constraints, attempts to apply solutions typical for the case-based reasoning method [2] (and similar or simpler versions of it) and multi-disciplinary optimization methods [7]. Starting such a task, usually the person in charge of solving the problem estimates (the estimation is based on his/her knowledge and intuition) the potential of such a problem, the level of its solvability, the adequacy of the methods and the tools which are used [3, 4]. The next stages are quite structurally (and tool-related) similar to the previous ones. They are only carried out at higher levels of complexity. Concepts that go beyond the standard functionalities appear somewhat separately, i.e. where it comes to sensing certain and typical states, the awareness of which requires models, a certain inference and the adoption of a sensible response strategy $[1,10,11,12]$ (an example of such a situation is shown in Fig. 3). It is basically a group design processes that concentrates on finding specific knowledge, which in a computer-modelled form can interact with a mechanical system to form a problem-oriented CPS subsystem.

\subsection{Multidisciplinarity and decision making}

Most project problems implemented today are also multidisciplinary [7]. These are tasks where specific design problems are used in their formalizations of knowledge that has been developed in various disciplines.

Design processes are also linked to decisions, decision-making structures or decision-making plans [2]. Decisions made by designers can be computer-aided. In many cases this leads to multidisciplinary optimization. Multidisciplinary optimization has its basic concepts, solutions and methods. It is usually used where there is a lack of experience and relevant knowledge concerning the product development process [13]. Multidisciplinary optimization is not an easy implementation tool. It involves specific knowhow to solve certain classes of problems, and to overcome formal and tooling difficulties. A very important aspect is the process of reaching an effective structure of a specific task of multidisciplinary optimization. The main issue is how to model a specific, complex design problem so that it has certain potential and brings new quantitative and qualitative effects. This is not a trivial issue. It is very difficult to implement.

\subsection{Diversity of considered problems}

The subject of the design process may be products of varying degrees of complexity. They can be classic products, classic products equipped with automation systems, mechatronic systems, or systems based on CPS concepts. In general, we can conclude that CPS systems are the most complex structures that, apart from those aspects that occur in classical design, may contain new components resulting from monitoring, control, etc., as well as the detection of various other circumstances that mean awareness of certain phenomena that allows us to initiate and control the functioning processes of relevant computer models. The considered case study is a problem with CPS elements. 


\section{The concept of an assisting tool}

\subsection{Block/template structures}

The material obtained in the analyzed example was used to create the concept of an assisting system in the design process of the product with CPS or its elements. The proposed concept is based on the creation of the possibility of modelling individual project activities using templates $[3,4,14,15]$. The template representing a specific activity is to serve as a repository in which it is possible to store the informal model of the given activity as well as its formal model [14]. Both variants of the knowledge model can be stored within the same version of the template. Another element of the template involves the decision-making models of given activities: the problem of selection on the basis of requirements, by the case-based reasoning (cbr) method, and classical inferencing and formalisms based on optimization methods. The concept introduces the possibility of combining decision-making formalisms as often occurring in real terms, e.g. combining cbr and optimization, etc. Additionally, in the template it is possible to store information on sources of knowledge related to particular components of a given template $[2,16,17,18,19,20]$. The presented concept of the template comes from the works [3, 4]. It is based on an approach known from the concept presented in the MOKA methodology [14]. The template is basically a model of a certain process during which the informal knowledge is transformed into a formal form. The content of the template can be used at any level, from informal (while creating the possibility of occurrence in many stages of development) to formal (also when creating the possibility of occurrence in many stages of development). Modelled knowledge resources can, depending on their form, be used as a kind of descriptive information intended directly for people as well as computerized automatic tools such as KBE (Knowledge Based Engineering) [14, 21, 22, 23, 24].

This concept, implemented in the form of a whole set of activities, allows the building of the processing based on different levels of built models. One can act only on descriptive models, and gradually lead the process of transitioning to the level of automatic tools with different degrees of perfection. In general, the financial rationality of the whole approach strongly specifies this solution. The construction of a complete automatic environment from the beginning is very complex and expensive. It is accompanied by quite a significant level of risk. The proposed evolutionary procedure gives the opportunity to rationalize the entire process.

\subsection{General structure of assisting system}

The concept of the system and its basic functionalities are presented in Fig. 5. There are two parts: "human way of problem modelling", "model-based problem solving". The first deals with the consolidation of informal knowledge and gradually emerging formal knowledge elements. The second includes formal models, their quickly remodelable forms concerning both analyses, simulations and decision modules. It is based on blocks / templates.

The formalism provides the possibility of integrating a set of model-related activities - the so-called partial models, both in their substantive and decision-making layers into larger entities called blocks.

CPS systems can have a whole range of references, resulting from their structure, implemented in the form of modelled views. These are: object layer, sensing layer, 
communication layer, analysis layer, and actuation layer $[1,10,11,12]$. This is shown in Fig. 5.

The main task of the tool with the presented concept is to improve the design process through more precise and problem-dedicated knowledge management and applied design models.

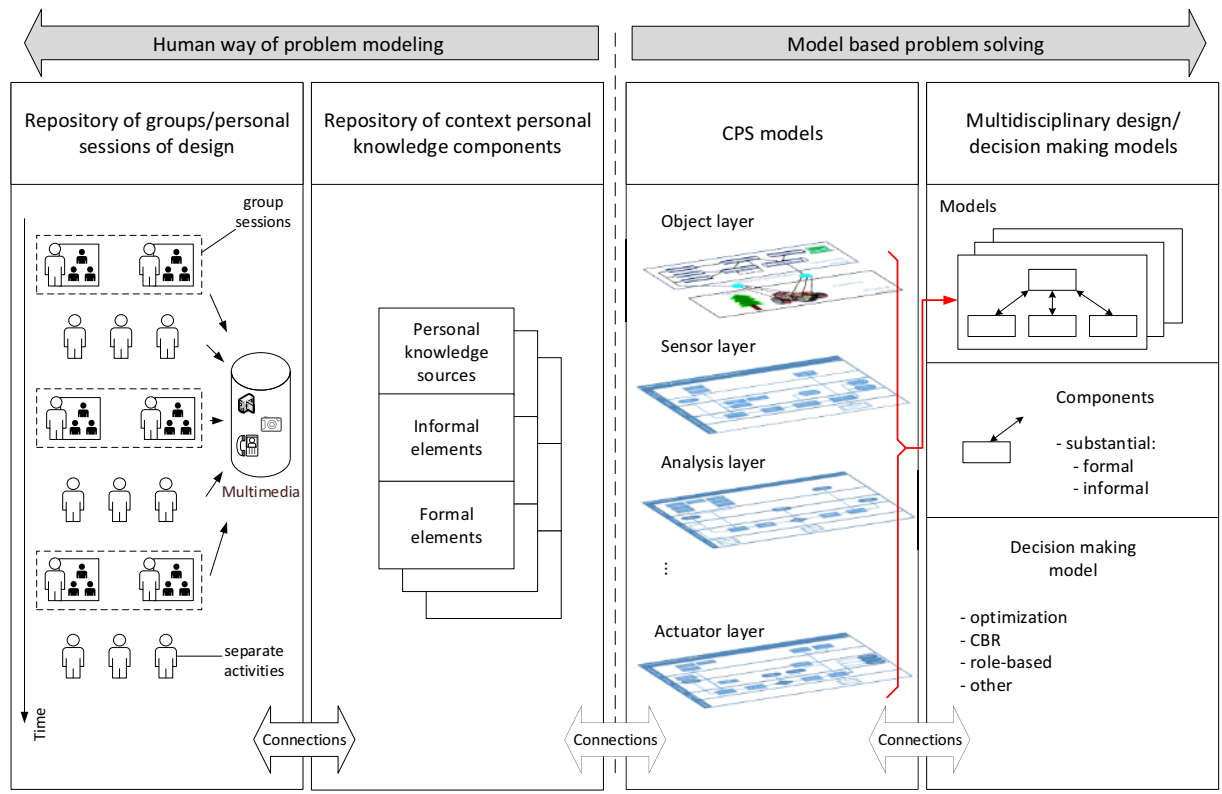

Figure 5. Repositories and models of assistive system.

\section{Conclusions}

The work contains a proposal for a dedicated environment to support the design process of systems with CPS elements. This article was inspired by a literature analysis and analysis of a real problem. The authors' belief is that one of the most important aspects of the concept is the ability to freely isolate the level of granularization of the entire set of modelled templates. The level of granularization has a decisive impact on the model's quality, its adequacy to reality, and also has a decisive impact on the quality of the results. Operating on this parameter allows the selection of the scope of individual activities, as well as the level of applied knowledge representations (informal and formal).

\section{Acknowledgments}

The authors wish to express their thankfulness to the BOGART GROUP, Dobre Miasto company for the invitation to participate in the project of designing the TCU. 


\section{References}

[1] L. Knap, Projektowanie i budowa zadaniowo zorientowanego systemu CPS (Design and Construction of the Task-Oriented CPS Systems), Wydawnictwo Naukowe Instytutu Technologii i Eksploatacji, 2017.

[2] J. Pokojski, IPA (Intelligent Personal Assistant) - Concepts and Applications in Engineering, SpringerVerlag, London, 2004.

[3] J. Pokojski, K. Oleksiński, J. Pruszyński, Knowledge based processes in the context of conceptual design, Journal of Industrial Information Integration, In Press, https://doi.org/10.1016/j.jii.2018.07.002 (it will appear)

[4] J. Pokojski, K. Oleksiński, J. Pruszyński, Conceptual and Detailed Design Knowledge Management in Customized Production - Industrial Perspective, Journal of Computational Design and Engineering, In Press, https://doi.org/10.1016/j.jcde.2019.02.004 (it will appear)

[5] D. Monticolo, J. Badin, S. Gomes, E. Bonjour, D. Chamoret, A meta-model for knowledge configuration management to support collaborative engineering, Computers in Industry, vol. 66 , 2015, pp. 11-20.

[6] D. Baxter, et al., An engineering design knowledge reuse methodology using process modelling, Res. Eng. Design, 18, 2007, pp. 37-48.

[7] J. Sobieszczanski-Sobieski, A. Morris and M. J.L. van Tooren, Multidisciplinary Design Optimization Supported by Knowledge Based Engineering, First Edition. John Wiley \& Sons, Hoboken, 2015.

[8] G. Pahl, W. Beitz, and al., Engineering Design: A Systematic Approach, Springer-Verlag, Berlin, 2007.

[9] D.G. Ullman, The Mechanical Design Process, Third Edition, McGraw-Hill, New York, 2002.

[10] C. Kan, C.J. Anumba, J.I. Messner, A Framework for CPS-Based Real-Time Mobile Crane Operations, In:I. Mutis and T. Hartmann (eds.), Advances in Informatics and Computing in Civil and Construction Engineering, Springer Nature Switzerland AG, 2019, pp. 653-660

[11] P. Hehenberger, B. Vogel-Heuser, D. Bradley, B. Eynard, T. Tomiyama, S. Achiche, Cyber physical systems design, methodology, and integration: the current status and future outlook, Computers in Industry 82 (2016), pp. 273-289

[12] A. Darwish, A. E. Hassanien, Design, modelling, simulation and integration of cyber physical systems: Methods and applications, J Ambient Intell Human Comput (2018) 9, pp. 1541-1556

[13] J. Stjepandic, N. Wognum, W.J.C. Verhagen, Concurrent Engineering in the 21st Century: Foundations, Developments and Challenges, Springer International Switzerland, 2015.

[14] M. Stokes, Managing Engineering Knowledge, MOKA - project, Professional Engineering Publishing Limited, London, 2001.

[15] S. Fenves, et al.: CPM: A Core Model for Product Data, Manufacturing Systems, Integration, Division, National Institute of Standards and Technology, Gaithersburg, USA Available at: http://www.mel.nist.gov/msidstaff/sriram. Accessed on: March 10th, 2007.

[16] S.K. Chandrasegaran, K. Ramani, R.D. Sriram, I. Horváth, A. Bernar, R. F. Harik, W. Ga, The evolution, challenges, and future of knowledge representation in product design systems, ComputerAided Design, vol. 45, 2013, pp. 204-228.

[17] S. Sim and A.H.B. Duffy, Towards an ontology of generic engineering design activities. Res. Eng. Design $14,2003,200-223$.

[18] S.B. Shooter, V.B. Keiroz, S. Szykman, S.J. Fenves, A Model for The Flow of Design Information in Product Development. Engineering with Computers, 16, 2000, pp. 178-194.

[19] S. Szykman, R.D. Sriram, Ch. Bochenek, J.W. Racz, J. Senfaute J., Design Repositories: Engineering Design's New Knowledge Base. IEEE Intelligent Systems, May/June, 2000, pp. 48-54.

[20] Y. Nomaguchi, K. Fujita, K., Knowledge representation framework for interactive capture and management of reflection process in product concepts development, Adv. Eng. Inform., vol. 27 , 2013, pp. 537-554.

[21] S. André, F. Elgh, J. Johansson, R. Stolt, The design platform- a coherent platform description of heterogeneous design assets for suppliers of highly customized systems, Journal of Engineering Design, vol. 28, 2017, pp. 1-28.

[22] W. J.C. Verhagen, P. Bermell-Garcia, R. E.C. van Dijk, R. Curran, A critical review of KnowledgeBased Engineering: An identification of research challenges. Advanced Engineering Informatics, Vol. 26, Issue 1, January 2012, pp. 5-15.

[23] V. Trehan, C. Chapman, P. Raju, Informal and formal modelling of engineering processes for design automation using knowledge based engineering. J Zhejiang Univ-Sci A (Appl Phys \& Eng) 2015 16(9), pp. 706-723.

[24] J. Stjepandic, W.J.C. Verhagen, H. Liese, P. Bermell-Garcia, Knowledge-Based Engineering, In: J. Stjepandic, N. Wognum, W.J.C. Verhagen, Concurrent Engineering in the 21st Century: Foundations, Developments and Challenges, Springer International Publishing, 2015, pp. 255-286. 